\title{
Evans on Intellectual Attention and Memory Demonstratives
}

\author{
Mark Fortney, The University of Toronto at Scarborough \\ mark.fortney@mail.utoronto.ca
}

\begin{abstract}
:
Intellectual attention, like perceptual attention, is a special mode of mental engagement with the world. When we attend intellectually, rather than making use of sensory information we make use of the kind of information that shows up in occurent thought, memory, and the imagination (Chun, Golomb, \& Turk-Browne, 2011). In this paper, I argue that reflecting on what it is like to comprehend memory demonstratives speaks in favour of the view that intellectual attention is required to understand memory demonstratives. Moreover, I argue that this is a line of thought endorsed by Gareth Evans in his Varieties of Reference (1982). In so doing, I improve on interpretations of Evans that have been offered by Christopher Peacocke (1984), and Christoph Hoerl \& Theresa McCormack (a coauthored piece, 2005). In so doing I also improve on McDowell's (1990) criticism of Peacocke's interpretation of Evans. Like McDowell, I believe that Peacocke might overemphasize the role that "memory-images" play in Evans' account of comprehending memory demonstratives. But unlike McDowell, I provide a positive characterization of how Evans described the phenomenology of comprehending memory demonstratives.
\end{abstract}




\section{$\underline{\text { 0. Introduction }}$}

In Principles of Psychology, William James distinguished between perceptual attention and intellectual attention - the attention we pay in careful thought or imagination as opposed to careful seeing or listening (James 1890 p. 416). Psychologists today continue to study intellectual attention under the heading of "internal attention" or "reflective attention", explicitly asserting that these new terms refer to the same phenomenon that William James called "intellectual attention" (Backer \& Alain, 2014, p. 439; Chun, Golomb, \& Turk-Browne, 2011, p. 77). When contemporary psychologists talk about internal rather external attention, in their view they are talking about attention that requires using information from mental representations that are stimulus independent rather than stimulus-dependent; i.e., representations that do not depend for their existence on active causal contact with a stimulus. ${ }^{1}$ For example, a visual experience of the sunset requires an active causal contact with the sunset; a memory, by contrast, does not. On this way of thinking, once the sunset is over, only internal or intellectual attention towards the sunset is possible.

But note that acknowledging the phenomenon of intellectual attention does not necessitate drawing the demarcation between perceptual and intellectual attention in this precise manner. The way contemporary psychologists draw this demarcation may be controversial, and worth further investigation. But what is less controversial is the claim that there is an intellectual kind of attention. Aristotle, for instance, notes in On the Sense and the Sensible that a perceptual or an intellectual kind of focus can both cause us to fail to

\footnotetext{
1 For more on the boundary between the perceptual and the cognitive see Burge 2010, p. 378; Beck 2012, p. 586; and Beck 2017. For this understanding of the boundary as it shows up in psychology and in the distinction between these two varieties of attention, see Chun, Golomb, \& Turk-Browne, 2011.
} 
notice what is going on around us when he writes: “... persons do not perceive what is brought before their eyes, if they are in deep thought, or in a fright, or listening to some loud noise". (Sens. 447a14-16, emphasis mine)

The distinction between these two kinds of attention puts us in a position to ask whether intellectual attention is ever necessary to understand certain kinds of speech. The perceptual analogue of this question has been extensively discussed in the recent literature, particularly with respect to the question of whether perceptual attention is ever required to understand perceptual demonstratives. ${ }^{2}$ The intellectual version of this question is, however, relatively under-explored, especially when we think of intellectual attention that manifests in occurrent thought rather than in memory. ${ }^{3}$

Moreover, there are a variety of ways that my broad question about intellectual attention and linguistic understanding could be made more precise. We could ask, for instance, whether linguistic understanding ever requires joint rather than solitary intellectual attention, or whether intellectual attention to propositions plays a role in the best account of linguistic understanding. ${ }^{4}$ In this paper, I restrict the scope of my discussion to the relatively simple and narrow question of whether intellectual attention is required to understand uses of "memory demonstratives". Memory demonstrates are demonstratives that refer to an object that two interlocutors can remember previously perceiving, but which the interlocutors cannot at present perceive.

\footnotetext{
${ }^{2}$ See e.g. Siegel 2002, Dickie 2011, and Smithies 2011.

${ }^{3}$ As my engagement with Hoerl and McCormack below demonstrates, there are some theorists who have considered the role attention and memory play together in speech comprehension.

${ }^{4}$ See Eilan, Hoerl, McCormack \& Roessler (eds. 2005) for some discussions of the phenomenon of joint attention, in particular joint perceptual attention.
} 
I argue that Gareth Evans, in The Varieties of References, has already argued for a "yes" answer to my simpler and narrow question about intellectual attention and memory demonstratives. But most readers of Evans don't seem to have noticed this fact and have misrepresented his account of what it takes to understand a memory demonstrative. In so doing I improve on interpretations of Evans that have been offered by Christopher Peacocke, John McDowell, Christoph Hoerl, and Teresa McCormack.

I attribute to Evans a view of attention very much like William James's view, according to which attention phenomenologically singles out an object from all the others like a spotlight can single out one object from all the other objects around it (James 1890 pp. 403-404; this is my gloss on James's claim that attention "focalizes" consciousness). I also attribute to Evans an awareness that there are at least two kinds of attention perceptual and intellectual attention, although I do not attribute to him any particular detailed manner of analyzing this distinction (e.g. in terms of stimulus independence and dependence).

The metaphor of spotlighting something in consciousness applies just as well to the cognitive part of the stream of consciousness as it does for the perceptual part of the stream of consciousness. When one is conscious of several objects on top of a cluttered table, one can focus on one's keys, thereby making them phenomenologically singled out from the mess of objects on the table. When one is conscious of several possible ways of responding to an argument, one can focus on the most promising method of reply, thereby making it phenomenologically singled out from the other possible pathways in thought that also seem possible. 
On my reading of Evans, this spotlighting function of attention is required to comprehend both perceptual demonstratives and memory demonstratives. One does not comprehend a perceptual demonstrative referring to one particular person in a crowded room until the right person is singled out in experience. Similarly, one does not comprehend a memory demonstrative referring to a past event until that past event is singled out in experience.

As I show below, while Evans is relatively explicit about the link that exists between perceptual demonstratives and perceptual attention, it takes more work to establish the claim about memory demonstratives and intellectual attention. I do not attribute this latter view to Evans on the basis of explicit claims he makes about the nature or phenomenology of intellectual attention. I also do not attribute either of this view to Evans on the basis of his deference to some particular psychologist's account of intellectual attention. While he does occasionally refer to psychology in Varieties of Reference, none of his references in that direction appear to elucidate his account of attention.

Instead, I attribute this view to Evans through a project of rational reconstruction. According to Evans, memory demonstratives are "information-invoking Russellian singular terms". I argue that it is a consequence of this claim that intellectual attention is required to understand a use of a memory demonstrative. It's also a consequence of this claim that perceptual attention is required to understand a use of a perceptual demonstrative, which adds to the relatively straightforward evidence for thinking that Evans endorses such a view.

This paper, therefore, has goals that pertain to both the history of analytic philosophy as well as contemporary analytic philosophy. Through improving on previous 
interpretations of Evans, the paper makes progress in the history of philosophy. And through bringing Evans's view to light, the paper opens up a range of interesting questions about intellectual attention and speech comprehension that analytic philosophers should be interested in investigating. ${ }^{5}$

Before setting out to accomplish the two goals main goals of the paper I just described, I'll explain what I mean by "linguistic understanding" and the more straightforward evidence that Evans saw a connection between perceptual attention and understanding a perceptual demonstrative.

\section{Linguistic Understanding and Perceptual Attention}

By "linguistic understanding", I mean the mental state that a person occupies when they comprehend some speech. There are several competing views about how to provide an analysis of linguistic understanding. According to some, it is knowing what was said by the speaker's production of the speech in question. ${ }^{6}$ According to some others, it is having a perceptual or quasi-perceptual experience of the speaker's meaning. ${ }^{7}$ According to yet others, it is having a cognitive experience of the speaker's meaning. ${ }^{8}$

Whichever of these views is the right one, the question of whether perceptual

\footnotetext{
${ }^{5}$ For more on the nature of intellectual or internal attention, see Fortney 2019, Fortney 2020a, Fortney $2020 \mathrm{~b}$.

${ }^{6}$ See Peacocke (1976) for a version of the knowledge thesis and criticism of simpler views according to which understanding is just knowing what was said. See Recanati (2004 pp. 5-9) for an explication of the notion of "what was said", and how it differs from "sentence meaning" and "what is implicated".

${ }^{7}$ See Hunter (1998) and Fricker (2003) for versions of the meaning perception thesis. On this approach we might characterize the content of the audience's experience (in part) what was said by the utterance.

8 See Longworth (2005) for this view of linguistic understanding. See Smithies (2011) for more on the distinction between cognitive experiences and perceptual experiences.
} 
attention is ever required to comprehend speech, and the question of whether intellectual attention is ever required to comprehend some speech, are both left unanswered. Further work is required to settle those questions.

When it comes to the unanswered question about perceptual attention and speech comprehension, it's common for philosophers to believe that intuitions about the phenomenology of conscious attention can help address the question - for instance, this is a view that's shared by both John Campbell (2003) and Gareth Evans (1982). Campbell and Evans both think that perceptual attention plays a role in the having a perceptual demonstrative thought, and consequently also in coming to understand a use of a perceptual demonstrative.

Here is how Campbell put this view about perceptual attention and linguistic understanding, along with what he took to be the intuitive motivations for the view.

... consider an ordinary case in which you and I are sitting at a dinner table with a large number of people around and you make a remark to me about 'that woman'. There are a lot of people around; I can't yet visually single out which one you mean. So on anyone's account, I do not yet know which woman you are talking about. Suppose now that we add to the example. My visual experience remains as before: a sea of faces. I cannot consciously single out the person you mean. All I get consciously is the sea of faces. ... It is only when I have finally managed to single out the woman in my experience of the room, when it ceases to be a sea of faces and in my experience I focus on that person, that I would ordinarily be said to know who was being referred to. So it does seem to be compelling to common sense that conscious attention to the object is needed for an understanding of the demonstrative (Campbell 2003 pp. 8-9).

As we can see, Campbell thinks that reflecting on what it is like to comprehend a perceptual demonstrative reveals that perceptual attention to the referent is required to comprehend 
the demonstrative. There is a difference between failing to attend to the referent and successfully attending to the referent, and what seems to make the difference is phenomenologically singling out the referent from all the other objects.

Here is how Evans puts the same sort of view:

... in order to have a demonstrative thought (one that rests upon perceptual information), the subject must be able to make the object out in what he perceives; and there is necessarily a gap between grasping 'The blonde who looks thus and so is $\mathrm{F}$ ' and 'That blonde is $\mathrm{F}$ ', because there is always room for an intelligible realization: 'Ah! So that's the blonde you mean! (Evans 1982 pp. 308-309).

Evans's claim that an audience's understanding a perceptual demonstrative requires "make the object out" seems to be a claim about consciously attending to the object in question. While he does not use the term "attention" in this passage, he is clearly referring to the exact same phenomenon of consciousness that Campbell referred to in the passage before, a phenomenon of consciousness that Campbell, and many other philosophers, such as James (1890) and Watzl (2018) think of as an effect of attention. So it's reasonable to think that Evans thought he was describing a subject perceptually attending when he was describing a subject that had "made the object out" in perception. And this becomes even more reasonable to believe when we consider this remark from the end of Chapter 6, which does explicitly link attention to perceptual demonstratives: "[the] fundamental basis, then, of a demonstrative Idea of a perceptible thing is a capacity to attend selectively to a single thing over a period of time..." (Evans 1982 p. 175, emphasis mine).

So Campbell and Evans both seem to endorse the idea that perceptual attention is required to understand a perceptual demonstrative. Moreover, Campbell and Evans both 
seem to endorse William James's idea that attention involves “... the taking possession by the mind, in clear and vivid form, of one out of what seem several simultaneously possible objects or trains of thought... Focalization, concentration, of consciousness are of its essence" (1890 pp. 403-404). Making out the right person in perception and singling out the right face in the sea of faces both seem like specific instances of the mind's taking possession, in clear and vivid form, of an object of thought.

Note that in joining James in endorsing this view about the phenomenology of attention, Campbell and Evans are not endorsing a mere platitude that any ordinary speaker competent with the word "attention" would endorse. Wayne $\mathrm{Wu}$, for instance, argues that attention has no distinctive, systematic impact on phenomenology, and that the claim that it does seem to phenomenologically single out one object from all the rest may be a product of reflection on special cases (Wu 2014 p. 130). The task of settling the dispute between Watzl, Campbell, and Evans, on the one hand, and Wu, on the other hand, is outside of the scope of this paper. But the existence of the dispute is important. It flags that Evans, in saying that we understand a perceptual demonstrative only when we have made out the referent in perception, is committing himself to a substantive thesis about the phenomenological function of attention.

\section{A Question About Memory Demonstratives}

So Evans's phenomenological claims about what it is like to understand perceptual demonstratives reveals his belief that perceptual attention is required to understand perceptual demonstratives, as does his explicit claim about the connection between attention and our perceptual demonstrative thoughts. Does he think something similar 
holds for memory demonstratives and intellectual attention?

Here is how he describes what it is like to comprehend a memory demonstrative:

... consider the following case. $S$ and $A$ were in the habit of going hunting together in their youth. On one of their hunting trips, they saw a dazzlingly beautiful bird perched in a pine tree. Years later, $S$ (the speaker) may advert to this incident, and say something like: 'Do you remember that bird we saw years ago? I wonder whether it was shot.' A (the audience) may not remember this episode. In order to jog his memory, $S$ may say 'Surely you remember; a hunting trip years ago; we saw, on a pine tree, a magnificent bird'... I do not think he can be said to have understood the remark, as it was intended to be understood, until he remembers the bird - until the right information is retrieved. (Evans 1982 p. 308).

His description of what it is like to comprehend this memory demonstration seems structurally similar to his description of what it is like to single out the right person in perception. At first, the audience is conscious of a range of different possible persons that the speaker might have in mind (in the perceptual case) or a range of different possible birds seen on hunting trips that the speaker might have in mind (in the case of memory). Then, the audience's conscious state changes in a way that enables understanding, and the change is one which involves becoming conscious of the right person or bird.

That being said, it's less obvious, in this case, whether Evans would have wanted to characterize this change in consciousness as one involving attention. In the perceptual case, he uses the language of making an object out, which seems to be what James had in mind with attention's focalizing an object in consciousness, or what Campbell had in mind with attention singling an object out in consciousness. But here, Evans just says that the audience needs to remember the bird and to retrieve the right information. These claims might implicate attention, but they do not obviously do so. It depends on what Evans means 
by "retrieve the right information".

In the next section of this paper, I argue that his understanding of "retrieving the right information" is an understanding that implicates intellectual attention. According to my argument, Evans thinks that perceptual demonstratives and memory demonstratives are singular terms that are "information-invoking" and "Russellian", and his definitions of "information-invoking term" and "Russellian" singular term commits him to the idea that attention is required to understand these terms - perceptual attention for perceptual demonstratives, intellectual attention for memory demonstratives.

\section{Attention \& Information-Invoking Russellian Singular Terms}

Evans describes the notion of an information-invoking Russellian singular term over the course of his attempt to make more rigorous the rough idea that there is a way of being particularly 'directly' or 'intimately' related to an object of thought :

Many philosophers today look at the theory of reference through essentially Russellian eyes. ... Like Russell, they recognize the possibility, perhaps as a limiting case, of thinking of an object by description ... But, again like Russell, they cherish the idea of a more 'intimate', more 'direct' relation in which a subject may stand to an object (a situation in which the subject would be 'en rapport with' the object), and the idea that when a subject and his audience are both situated vis-a-vis an object in this way, there exists the possibility of using singular terms to refer to, and to talk about, that object in a quite different way, expressing thoughts which would not have been available to be thought and expressed if the object had not existed. (Evans 1982 p. 64)

Evans wanted to give an account of what it is to be in a "more intimate" or "more direct" or "en rapport" relationship with an object of thought. On his view, when we are thinking of an object in such a way, our thoughts are about object by the lights of Russell's Principle, 
according to which "a subject cannot make a judgment about something unless he knows which object his judgment is about" (Evans 1982 p. 89). Of course, maintaining such a commitment requires explaining what it is to have such "knowledge which".

Evans's way of explaining what it is for a subject to know which object their judgment is about is to say that the subject must have "discriminating knowledge" of such an object - i.e., a capacity to pick out the object of that judgment from all other things. He thought, for example, that if we can perceive an object, or if we have mastered the use of a proper name of an object, then we have discriminating knowledge of the object (Evans 1982 p. 91, p. 403). ${ }^{9} \mathrm{He}$ calls the kind of thoughts we have when we are in such a position "Russellian", and he calls the terms such that an audience needs to think a Russellian thought in order to understand it a "Russellian singular term" (Evans 1982 p. 91).

Throughout The Varieties of Reference, one of Evans's primary goals was to argue that various different kinds of "information-invoking" singular terms are also "Russellian" singular terms. According to Evans, "information-invoking" singular terms are terms such that, when a speaker uses them in an utterance, the audience needs to use some information available to her in order to understand the utterance (Evans 1982 pp. 305306). "Russellian" singular terms are terms that belong to a category of singular terms such that nothing is said by someone who utters a sentence containing such a term unless the term has a referent (Evans 1982 p. 71).

\footnotetext{
${ }^{9}$ Here Evans refers to perception rather than attentive perception. I think that it's best to interpret Evans as speaking loosely here - after all, as I've already pointed out, he's argued that it's attentive perceptual experience and not just perceptual experience that really enables us to understand perceptual demonstratives.
} 
For example, if perceptual demonstratives are Russellian singular terms, then a speaker who hallucinates and seems to see a dagger and utters "That's sharp", intending to refer to the dagger that doesn't exist, has actually said nothing at all. This view is, as Evans frequently acknowledges, a startling one. It certainly seems like there is something it is like to understand an utterance like "That's sharp", said of a hallucinatory dagger. Nevertheless, Evans thought that maintaining the view that some singular terms are Russellian was important enough that this startling aspect of his view was something to be explained away, rather than a sign of a genuine problem (Evans 1982 p. 129-132). Arguments for this kind of view appear in various parts of Varieties of Reference. In Chapter 6, for example, Evans argues that "here" and perceptual demonstratives are Russellian (Evans 1982 p. 170, p. 173). In Chapter 9, Evans takes a different approach, and offers a general argument that any information-invoking term is Russellian, including memory demonstratives (Evans 1982 p. 326).

In this paper, I will remain neutral on the question of whether it would actually be a good idea to cash out Russell's intuitive picture of the distinction between two ways of thinking about an object in the way that Evans wants to. I will also remain neutral on whether Evans's arguments that information-invoking singular terms are Russellian singular terms are actually successful. Instead, I will emphasize that if he believes perceptual and memory demonstratives are information-invoking Russellian singular terms, then he believes attention is required to understand these terms - perceptual attention for perceptual demonstratives, intellectual attention for memory demonstratives. This belief is one that is actually overdetermined for Evans. It follows both from the idea that memory demonstratives are Russellian singular terms, and from the idea that memory 
demonstratives are information-invoking singular terms. Below, I make these points in turn.

As I explained above, on Evans's view, Russellian thoughts are supposed to be "intimate", "direct", or "en raport" ways of being related to an object. But consider William James's apt characterization of the phenomenology of inattentive engagement with an object, which appears in the second half of the passage below:

"Everyone knows what attention is. It is the taking possession by the mind, in clear and vivid form, of one out of what seem several simultaneously possible objects or trains of thought. Focalization, concentration, of consciousness, are of its essence. It implies withdrawal from some things in order to deal effectively with others, and is a condition which has a real opposite in the confused, dazed, scatterbrained state which in French is called distraction, and Zerstreutheit in German." (James 1890 pp. 403-404, emphasis mine)

A mode of engagement with an object which is confused, dazed, and scatterbrained seems to be the opposite of whatever an "intimate", "direct", or "en raport" mode of engagement with an object would be. This is a reason to think that when a thinker understands a Russellian singular term, she must be in a relationship with the referent of the term that is attentive rather than inattentive.

Consequently, the flash of recollection in described in Evans's hunting trip passage must be a thought that involves intellectual attention to an object, and not just any cognitive mode of engagement with an object (like inattentive, distracted thought). Similarly, making out the person blond in perception, in Evan's passage about realizing which blond person the speaker referred to, must describe perceptual attention to a person rather than a scatterbrained or dazed mode of perception. Failing to say that these modes 
of engagement are attentive modes of engagement fails to do justice to Evans's idea that when we understand such terms, our connection to the referents of the terms is intimate, direct, or en raport. This is why we must say that according to Evans, attention is required to understand Russellian singular terms- perceptual attention for perceptual demonstratives, intellectual attention for memory demonstratives

Now we can consider the connection between attention and the idea of an "information-invoking" singular term. Consider the following passage, in which Evans says that when a speaker uses an information-invoking term, the speaker has the intention to get her audience to attend to a particular object:

... the notion of the intended referent is rather like the notion of a target. Suppose the subject, in the case we have been considering, had aimed a gun at the man he could see. Even if his general plan was to shoot $b$-for example, because the offence he wished to avenge occurred in the previous encounter- it is undeniable that a was his target, and that he intended to shoot $a$. His lowest-level action plan concerned a; success in it would involve the shooting of a. Similarly, a is the speaker's linguistic target when he utters the sentence 'That man over there is F'; this time he is directing, not a gun, but his audience's attention. (Evans 1982 p. 317, emphasis mine)

This passage lends weight to the idea that we should interpret Evans, in his descriptions of cases of audiences that have successfully understood information-invoking terms (e.g., the audience making out the right person in perception or the audience thinking of the right bird) as making claims that implicate attention rather than inattentive perception or inattentive memory. Less obviously but more importantly, this passage lends further weight to the idea that we should understand Evans's account of attention as one that is close to something like James's, according to which attention phenomenologically singles out an object from all the other ones. 
As the passage above makes clear, Evans thinks that a speaker using an information invoking term tries to achieve her communicative goals through directing the attention of her interlocutors. So the state of attending to the intended referent must be, in Evans's view, a state which puts an audience in a position to realize what the intended referent was. On the hypothesis that Evans endorsed something like James's view of attention, we have an explanation of why this makes sense. Attention phenomenologically singles out an object from all the others, on this way of thinking, which is why attending to an object puts an audience in a position to identify the intended referent. If we do not attribute to Evans the Jamesean view of attention, then Evans's use of the word "attention" in the passage above would be either mysterious (because attention would be performing some unknown theoretical role) or superfluous (because if attention had no theoretical role to platy, there would be no reason to mention it).

So the main argument of this paper has concluded. While Evans did not explicitly state that intellectual attention is required to understand a memory-demonstrative, he did state that memory-demonstratives are information invoking Russellian singular terms. When we comprehend a Russellian singular term; we are in an en raport relation with an object, a relation best characterized as attentive rather than inattentive. When we hear an information-invoking singular term, the speaker wants us to have an attentive experience with phenomenologically singles out the referent of the term, and having such an attentive experience puts us in a position to understand what the speaker has said. So Evans's belief that memory demonstratives are information invoking Russellian singular terms commits him, in two different ways, to the idea that intellectual attention is required to comprehend memory demonstratives. 


\section{Other Interpreters of Evans}

My account of Evans puts us in a position to move two separate conversations in the literature forward: one between Peacocke and McDowell about whether Evans thought that imagery plays a role in comprehending memory demonstratives, and another one involving Hoerl and McCormack about the relationship between attention and the use of information in the framework that Evans developed. I'll discuss these points in turn.

\section{$\underline{5.1}$ Peacocke and McDowell}

In Chapters 5 and 6 of his Sense and Content, Peacocke compared his view of understanding demonstratives to Evans' view of understanding demonstratives, and argued that his own account was superior in several respects (McDowell 1990 p. 255). In Peacocke's comparison of their views on understanding memory demonstratives, Peacocke mostly used the term "memory-image demonstrative" rather than "memorydemonstrative" (see e.g. Peacocke 1984 p. 126, p. 173). According to a review by John McDowell, Peacocke's terminology might reveal a flawed understanding of memorydemonstratives, which overemphasizes the role that imagery plays in their comprehension, and perhaps moreover even reveals that Peacocke mistakenly attributes the same flawed understanding to Evans. McDowell thinks that because Evans preferred to use the term "memory-demonstrative", leaving out references to "images", we should not assume that imagery did any work in Evans's account (McDowell 1990 p. 260, p. 264).

I agree with McDowell's core critical point - experiencing a particular memorial image of an absent object doesn't seem either necessary or sufficient for understanding a reference to the object in question. But I also think that McDowell's line of thought needs 
fleshing out. If it's true that the understanding a memory-demonstrative does not require experiencing a mental image of the referent of the term, then what is it actually like to understand a memory-demonstrative? What is phenomenologically distinctive about this kind of experience? This is a question that McDowell leaves unanswered in his criticism of Peacocke, and a question that my reading of Evans is able to answer.

Before going on to explain how I can answer this question, I should note that as a referee for this journal points out, this objection may be uncharitable to Peacocke. He does not define "memory-image" in Sense and Content, and he does not clarify his understanding of memory-image in his 1991 reply to McDowell published in Mind. It's possible that by "memory-image", Peacocke just meant "memory experience", which could encompass more kinds of experiences than memory images. And if this is all that Peacocke meant, then McDowell's criticism of him would not apply. However, if this is all that Peacocke meant, then Peacocke's account still leaves unanswered the same question that McDowell's account leaves unanswered: namely, what is it actually like to comprehend a memory demonstrative? Can we say something more substantive than just the claim that a subject must have a certain kind of experience that seems like a memory? According to my reading of Evans, we can.

As I've argued above, what Evans actually thinks is that understanding a memorydemonstrative seems to requires attending to the referent of the term, and thereby having an experience that is in some sense analogous to the experience of "making out" the right person in perception while comprehending a perceptual demonstrative referring to the person, or singling out the right method of reply to an object when several replies to the 
objection all seem possible. During such an experience, the remembered object would become singled out from all the other objects in the thinker's experience. So understanding Evans's position as I do allows us to provide a phenomenologically detailed answer to the question that McDowell's account, as well as the more charitable version of Peacocke's account, both left unanswered.

\section{$\underline{5.2 \text { Hoerl and McCormack }}$}

I will move on to consider another mistaken interpretation of Evans's account of memory-demonstratives, according to which he does not actually think that any kind of attention is required to understand them. In their paper "Joint Reminiscing as Joint Attention to the Past", Christoph Hoerl and Teresa McCormack first argue that "episodic recall uniquely involves the particular form of attention, which might be described as attention to particular past events" (Hoerl and McCormack pp. 263-265). Then they go on to argue that there is a sense in which people can jointly attend to past events together, just like they can jointly perceptually attend together to nearby objects in the environment (Hoerl and McCormack pp. 263-265 p. 283). They think that when we talk about past events with each other, we employ such a capacity.

While they pursue their first goal, they compare the way that they think that thought and talk about past events functions to the way that Evans thinks that thought and talk about past events functions. On Hoerl and McCormack's view, Evans doesn't think that intellectual attention is required for episodic recall, and moreover, they argue, this alleged feature of his view is a problem for him. This is how they characterize Evans's view:

Consider the following example, adapted from Alfred Ayer (1956) and Gareth Evans (1982; see also Campbell, 2001). Suppose that a friend tries to remind you of an incident in your past of which she was a witness... Suppose also, however, that after a while, the 
incident does come back to you. This may happen quite suddenly, 'in a flash of recollection', as Evans (1982 p. 308 puts it). The question now is: How should we describe what happened to you-i.e. what this change in your state amounts to?

Evans thinks that the change at issue can be described as a change in the causal history of your state. As he puts it, the relevant state of recollection only sets in once 'the right information is retrieved' (ibid)-i.e. information that traces back to your own experience of the incident. ... [but as] the literature on priming brings out, there are a number of ways in which particular past experiences can have a causal influence on a person's subsequent mental state in the absence of conscious recollection (c.f. e.g. Mayes, 2001, for examples). Thus, it is not clear why we should rule out the possibility that your friend's attempts to jog your memory succeeded in activating information retained from your experience of the incident, even before the flash of recollection occurred. Indeed, such information might play a part in explaining your ability to form an accurate mental image say, of the location and people involved. (Hoerl and McCormack p. 264).

On Hoerl and McCormack's way of interpreting Evans, whether an audience trying to understand a memory demonstrative has retrieved the right information depends entirely on the causal connection between the audience's current informational state and the past event. Hoerl and McCormack seem right to say that such an account of understanding memory-demonstratives seems inadequate.

As they say, even when a causal link is present, and information from a past event is having an effect on the subject's present state, the audience might not have the characteristic experience of understanding the memory-demonstrative. The audience might instead have an experience that is causally influenced by the previously perceived object, but in a subliminal way, and in a way that does not facilitate comprehension of the memory demonstrative. Hoerl and McCormack go on to argue that a subject's making the right use of the information, rather than just being causally affected by the right 
information, is sufficient for attention, and that such a way of attending is required to understand the reference to the past event (Hoerl and McCormack pp. 263-265 p. 283). ${ }^{10}$

But Hoerl and McCormack seem to have misunderstood Evans's account. They say that according to Evans, after the flash of recollection, the only thing that has changed about the subject is the causal history of her informational state. However, consider what Evans writes immediately before his description of this case involving recollection: "Understanding the kind of use of a referring expression I am referring is to not a matter of having beliefs with the right sort of content, but having, and using, information from the right source" (Evans 1982 p. 307, emphasis mine).

Hoerl and McCormack's criticism would be correct if Evans had not said "and using" in the preceding sentence. But Evans's phrase "... and using ..." - which shows up throughout the text in his characterizations of information-invoking expressions - reveals that he thinks that experiencing the flash of recollection requires not just the audience's being causally influenced by the right bird, but also the audience's using that information to interpret the speaker's remark.

Evans describes explicitly what this process of using the right information is, as applied to a perceptual case, earlier in the same chapter: “... if a speaker utters "This man is $\mathrm{F}^{\prime}$, making a demonstrative reference ... the hearer can understand the remark only if he perceives the man concerned, and, bringing his perceptual information to bear on the interpretation of the remark, judges 'This man is F: that's what the speaker is saying".

\footnotetext{
${ }^{10} \mathrm{~A}$ further question to ask and address is whether the cognitive representations we employ in understanding memory-demonstratives merely enable understanding, or themselves contribute to the epistemic standing of our states of linguistic understanding (see, e.g. Burge 1993 p. 481 for a discussion of whether perception enables or justifies the knowledge we acquire through testimony). I don't take up the issue here, but am inclined to argue that, in general, our uses of information from both cognitive and perceptual representations contribute to the epistemic standing of our states of understanding.
} 
(Evans 1982 p. 305) So in the recollection case, Evans would say that the audience needs to have information from the bird in order to interpret the remark, but that having this information is insufficient for comprehending the memory demonstrative referring to the bird. The audience would also need to bring their information to bear on their interpretation in just the same way. So it is a mistake to say that according to Evans, mere priming could cause the audience to be in an informational state counts as understanding the memory-demonstrative. In cases of mere priming, a subject is not actively using the information and bringing it to bear on how she is interpreting a speaker's remark.

Hoerl and McCormark go on to argue that in order to understand memorydemonstratives, we need to use our attention rather than by merely causally influenced by the right information, and they construe attention in terms of a subject's using information to answer questions about her past environment. (Hoerl and McCormack p. 266) As we're now in a position to appreciate, at this level of abstraction their account is effectively identical to Evans's own account, in that Hoerl \& McCormack and Evans all believe that using the right information is an important part of comprehending a memory demonstrative. Moreover, if the main argument of this paper is successful, then for Evans this particular use of information is a kind of use of information that deserves to be called "attention", which brings the accounts of Hoerl \& McCormack and Evans even closer together.

While Hoerl \& McCormack endorse the same kind of view Evans does, according to which using the right information is required to comprehending a memory demonstrative, it's worth noting that there is still much that is novel and worthwhile about their articulation of the view. They situate their view about attention and memory 
demonstratives in relation to the idea that agents can play an active role in processes like looking and remembering, with reference to work by Ulric Neisser, Naomi Eilan, and Johannes Roessler (Hoerl and McCormack p. 265). Evans, by contrast, does not do as much work to situate his account of using the right information in relation to a broader view about agency and mental processes.

\section{Conclusion}

As I noted above, distinguishing between perceptual and intellectual attention puts us in a position to ask a variety of interesting questions about intellectual attention and linguistic understanding. I've made some headway on addressing one of the simpler questions that such a distinction enables us to ask: is intellectual attention ever required to understand a memory demonstrative? I argued that Evans is at least one philosopher who would give a "yes" answer to that question. I argued that the best way to interpret his remarks about the phenomenology of understanding memory-demonstratives was in terms of the effects of conscious intellectual attention. On my view, Evans thinks that when we understand a memory-demonstrative we have an attentive experience which phenomenologically singles out the referent of the memory-demonstrative from all the other objects.

There are further questions to be asked about the epistemic role intellectual attention plays in communication, and in our mental lives more broadly. When it comes to future investigations into communication, as I noted in the introduction, we might extend my discussion in this paper to ask whether linguistic understanding ever requires joint rather than solitary intellectual attention, or whether intellectual attention to propositions 
plays a role in the best account of linguistic understanding. When it comes to future investigations into our mental lives, we might ask what sorts of tasks are possible with and without intellectual attention, and whether it plays a role in inference. Through my work here - providing a case studying of intellectual attention playing a particular functional role - I've helped set the foundation for future studies like these.

\section{References}

Backer, K., and Alain, C. (2013). Attention to memory: orienting attention to sound object representations. Psychological Research, 78(3), 439-452.

Barnes, J. (1984). Complete Works of Aristotle. Princeton, NJ: Princeton University Press.

Beck, J. 2012. "The Generality Constraint and the Structure of Thought." Mind 121: 563600.

Beck, J. 2017. "Marking the Perception-Cognition Boundary: The Criterion of StimulusDependence." Australasian Journal of Philosophy 96 (2): 319-334.

Burge, T. (1993). "Content Preservation”. The Philosophical Review. 102: 457-488.

Burge, T. 2010. Origins of Objectivity. Oxford: Oxford University Press.

Campbell, J. (2003). Reference and Consciousness. Oxford University Press.

Chun, M., Golomb, J., and Turk-Browne, N. (2011). "A taxonomy of external and internal attention". Annual Review of Psychology, 62: 73-101.

Dickie, I. (2011). "Visual Attention Fixes Demonstrative Reference by Eliminating Referential Luck." C. Mole, D. Smithies, and W. Wu (eds.), Attention: Philosophical and Psychological Essays. Oxford University Press.

Hunter, D. (1998). "Understanding and Belief". Philosophical and Phenomenological Research 58: 559-580.

Fortney, M. (2019).“Conceptualizing intellectual attention". Theory \& Psychology. 29(6): 775-788.

Fortney, M. (2020a). "Unity in the scientific study of intellectual attention." Canadian Journal of Philosophy. 50(4): 444-459. 
Fortney, M. (2020b). "Directing internal attention towards ongoing thought". Consciousness and Cognition. [online]

Eilan, N., Hoerl, C., McCormack, T., and Roessler, J. (eds). (2005). Joint Attention, Communication, and Other Minds. Oxford University Press.

Fricker, E. (2003) “Understanding and Knowledge of What is Said". In: Epistemology of Language. Ed. by A. Barber. Oxford University Press, 2003, pp. 325-365.

Evans, G. (1982). Varieties of Reference. Oxford University Press.

Hoerl, C. and T. McCormack. (2005). "Joint reminiscing as joint attention to the past". In N. Eilan et al. (eds), Joint Attention: Communication and Other Minds. Ed. by N. Eilan et al. Oxford University Press.

James, W. (1890). The Principles of Psychology. Cambridge, MA: Harvard University Press.

Longworth, G. (2005). "Some Models of Linguistic Understanding". The Baltic Yearbook of Cognition, Logic, and Communication 5: 1-56.

McDowell, J. (1990). “Peacocke and Evans on demonstrative content”. Mind 99. 255-266.

Peacocke, C. (1976).“Truth Definitions and Actual Languages”. In: Truth and Meaning. Ed. by J. McDowell and G. Evans. Oxford University Press, pp. 162-168.

Peacocke, C. (1984). Sense and Content. Oxford University Press.

Peacocke, C. (1991). "Demonstrative content: A reply to John McDowell”. Mind 100 (1):123133.

Recanati, F. (2004). Literal Meaning. Cambridge University Press.

Sigel, S. (2002). "The Role of Perception in Demonstrative Reference". Philosopher's Imprint (2): 1-21.

Smithies, D. (2011). "Attention is rational-access consciousness". In C. Mole, D. Smithies, and W. Wu (eds.), Attention: Philosophical and Psychological Essays. Oxford University Press.

Wu, W. (2014). Attention. New York: Routledge. 